PAPER SET FOR EXAMINATION FOR THE CERTIFICATE IN PSYCHOLOGICAL MEDICINE, 19TH DEOEMBER, 1895.

1. State Fechner's law : illustrate it by diagrams. State the ratio between stimulus and sensation in the case of light, heat and sound.

2. Describe the condition Pachymeningitis hromorrhagica interns, and state your views as to its Etiology.

3. What is Cretinism ? What is the usual mental condition associated with it ? Describe a case.

4. What do you understand by Moral Insanity ? Disouss its Modico-legal aspects and describe any case which may have come under your notice.

5. Describe what is meant by Circular Insanity. State prognosis and treatment.

6. Describe the course and treatment of a typical case of Epileptic Insanity. Discuss Larval Epilepsy in its relation to impulsive acts and oriminal responsibility.

All the questions to be answered.

\title{
DATES OF NEXT MEETINGS OF THE ASSOCIATION.
}

The next General Meeting will be held on Thursday, May 21st, at the Rooms of the Association, 11, Chandos Street, Cavendish Square, W.

The next Meeting of the Irish Division will be held on Thursday, May 14th, in Dublin.

The Spring Meeting of the South-Western Division is to be held at Bailbrook House, Bath (instead of at Barnwood House, Gloucester, as previously announced), on Tuesday, April 14th. After the business, "The Roport of the Committee on Criminal Responsibility " will be discussed, and the Hon. Secretary is to introduce a discussion on "The Nursing Staff in Asylums."

It is expected that the Annual Meeting of the Association will be held on the third Thursday of June, 1896.

\section{CONGRESS AT NANCY.}

The Seventh Annual Congress of French-speaking Alienists and Neurologists will be held at Nancy on the 1st August, 1896, under the presidency of $M$. Pitres, of Bordeaux. Among other subjects will be discussed: (1) The Pathogenesis and Physiology of Hallucinations of Hearing; (2) The Bemeiology of Tremblings; (3) The Reception of the Insane into Asylums, in its Therapeutio and Legislative Aspects.

\section{CONGRESS AT MUNICH.}

As previously announced, the third International Congress of Psychology will be held at Munioh from 4th to 7th August, 1896.

\section{APPOINTMENTS.}

Drspard, Miss R. C., M.B. London, has been appointed Junior Assistant Medical Officer at the Holloway Sanatorium Hospital for the Insane, Virginia Water, vice Miss Emily Dove, now Assistant Medical Officer at the Iondon County Asylum, Claybury.

Grems r, Thomas Adriay, Dr., has been appointed Assistent Medical Officer at the District Lunatio Asylum, Ennis.

HarRIs, T., M.D. Lond., has been appointed Visiting Physician to the Manchester Royal Lunatic Asylum.

Watson, William Riddele Kemlo, M.A., M.B., C.M. Glasgow, has been appointed Junior Assistant Medical Officer at Devon County Asylum. 